\title{
In Their Own Voices
}

\section{A Qualitative Study of Women's Risk for Intimate Partner Violence and HIV in South Africa}

- Ashley M. Fox

- Sharon S. Jackson

Nathan B. Hansen

- Mary Crewe

- Kathleen J. Sikkema

Ashley M. Fox, MA, is a doctoral candidate in the Department of Sociomedical Sciences at the Mailman School of Public Health, Columbia University.

Sharon S. Jackson, MA, Yale University, is a senior research officer at the Institute for International Integration Studies, Trinity College Dublin.

Nathan B. Hansen, $\mathrm{PhD}$, is assistant professor in the Department of Psychiatry, Yale University School of Medicine.

Nolwazi Gasa, MA, is a public health specialist at the Development Bank of Southern Africa, Midrand, Republic of South Africa.

Mary Crewe is the director of the Centre for the Study of AIDS (CSA) at University of Pretoria, Republic of South Africa.

Kathleen J. Sikkema, PhD, is professor of nursing, psychology, and psychiatry at Duke University

This study qualitatively examines the intersections of risk for intimate partner violence (IPV) and HIV infection in South Africa. Eighteen women seeking services for relationship violence were asked semistructured questions regarding their abusive experiences and HIV risk. Participants had experienced myriad forms of abuse, which reinforced each other to create a climate that sustained abuse and multiplied HIV risk. Male partners having multiple concurrent sexual relationships, and poor relationship communication compounded female vulnerability to HIV and abuse. A social environment of silence, male power, and economic constraints enabled abuse to continue. "Breaking the silence" and women's empowerment were suggested solutions. 
Violence against women (VAW) is a global problem affecting between $10 \%$ and $60 \%$ of women and cutting across social, economic, religious, and racial lines (Heise, Ellsberg, \& Gottmoeller, 2002). Perhaps the most common form of VAW is that inflicted by an intimate male partner (World Health Organization [WHO], 2002). Intimate partner violence (IPV) has been defined to include physical and sexual violence, threats of violence, and psychological and emotional abuse (WHO, 2002). The perpetrator may be a current or former spouse, boyfriend or girlfriend, or dating partner (Flinck, Paavilainen, \& Åstedt-Kurki, 2005; Watts \& Zimmerman, 2002). Across 48 population-based surveys from 34 different countries, between $10 \%$ and $69 \%$ of women reported being physically assaulted by an intimate male partner (WHO, 2002).

Though accurate statistics are difficult to obtain (Gilbert, 1996; Wood, Maforah, \& Jewkes, 1998), results from various studies in South Africa reveal high rates of physical and sexual violence. For example, the South African demographic health survey found that $13 \%$ of women have been assaulted by an intimate partner at some point (Department of Health, 1998), whereas a study of 3 South African provinces found that $19 \%$ to $27 \%$ of women reported IPV (Jewkes, Penn-Kekana, Levin, Ratsaka, \& Schrieber, 2001). A study of 1,394 male workers found $15 \%$ of men reported having raped or attempted to rape a wife or girlfriend (Jewkes \& Abrahams, 2002). Other studies have revealed rape, sexual coercion, forced sexual initiation, and femicide as realities for many women and girls in South Africa (e.g., Gilbert, 1996; Human Rights Watch, 1995; Jewkes, Vundule, Maforah, \& Jordaan, 2001; Wood \& Jewkes, 1997).

With an estimated 40 million people living with HIV/AIDS worldwide, subSaharan Africa continues to be the most affected region, with $70 \%$ of all AIDS cases (UNAIDS, 2003). Of the people living with HIV/AIDS in sub-Saharan Africa, 55\% are women (WHO, 2000), with about twice as many young women (aged 15-24) than men infected overall (UNAIDS, 2003). With more than 5 million people living with HIV, South Africa has more infections in absolute terms than any other country (national adult HIV prevalence of 20.1\%; UNAIDS, 2002). In addition, $57.0 \%$ of these cases occur in women (UNAIDS, 2002). The disparities in infection rates between men and women have led some to note the "gendered" nature of the epidemic (e.g., Roth \& Hogan, 1998; Umerah-Udezulu, 2001).

Explanations for this gender disparity in HIV infections in sub-Saharan Africa have focused on women's biological, economic, social, and cultural "vulnerability" to contracting HIV/AIDS (Amfar, 2005; WHO, 2000). ${ }^{1}$ Women, who frequently have a subordinate status in society, have limited ability to negotiate safer sex. Economic dependency may make a woman more open to coercion and place women in a position requiring an exchange of sex for money or housing (Gilbert, 1996; Gilbert \& Walker, 2002; WHO, 2000). Furthermore, there is a growing awareness that gender-based violence and the HIV/AIDS epidemic interact to increase women's risk for both HIV and abuse, particularly in sub-Saharan Africa (e.g., Maman, Campbell, Sweat, \& Gielen, 2000). 
Although IPV is a serious health problem in its own right (WHO, 2000), one of the most detrimental consequences of IPV is increased HIV risk for women. A review of 29 studies from North America and sub-Saharan Africa found that violence may put women at heightened risk for HIV through forced or coerced sex with an infected partner, inhibiting negotiation of safe sex, and childhood sexual abuse (CSA), setting a pattern of sexual risk-taking behavior (Maman et al., 2000). In addition, discussion of HIV or disclosure of serostatus to partners may heighten women's risk for violence (Maman et al., 2000). Evidence suggests that VAW may limit the impact of HIV prevention strategies, as violence may prevent abused women from reducing their number of partners, using condoms, or accessing medical care (Heise \& Elias, 1995). Other studies indicate that gender norms and female economic dependency limit women's ability to negotiate safer sex (Gupta \& Weiss, 1993; Santow, 1995; Worth, 1989).

Furthermore, a study of women attending antenatal clinics in Johannesburg revealed women's involvement in an abusive or controlling relationship with a male as a primary risk factor for HIV. This was found to surpass even the risks of having multiple and nonprimary partners, engaging in transactional sex, and having problems with substance abuse (Dunkle et al., 2004). Abusive men have been postulated to be more likely to have HIV and impose risky sexual practices on partners (Dunkle et al., 2004).

Reviews of literature on VAW and HIV risk have noted that qualitative research is particularly valuable to understand the context, power dynamics within relationships, and multiple social factors that influence IPV (Maman et al., 2000; Parker, 2000). Understanding and interpreting the cultural constructions of sexuality in different communities have revealed important ways in which social roles constrain women's ability to protect themselves from HIV (Parker, 2000). According to Obermeyer (2005), qualitative research has been especially useful in calling into question the "rationalizing, medically informed, and risk-averse frameworks underlying most surveys” (p. 9).

Previous anthropological and ethnographic research on the topic of rape and sexual coercion in South Africa has revealed that differing notions of sexual consent and free agency may mean that prevalence rates of forced or coerced sex are especially difficult to capture in quantitative studies. For example, Jewkes and Abrahams (2002) explain,

Most women have such low expectations of genuine sexual negotiation in relationships that being forced to have sex when men (husbands, boyfriends or often would-be lovers) want it, or provide it as a unit of exchange, is seen as “normal.” (p. 1233)

Similarly, in their formative study on adolescent women's experiences with reproductive health, Wood and Jewkes (1997) found that "physical assault was so commonplace that women stated that many of their female peers saw it as an expression of love” (p. 42). 
High-level debates about the magnitude of violence and rape in South Africa have periodically surfaced since the institution of a multiracial democracy in 1994 (Jewkes \& Abrahams, 2002). Although studies of violence in South Africa have noted a "culture of violence" as generally contributing to the high rates of IPV (Jewkes \& Abrahams, 2005; Outwater, Abrahams, \& Campbell, 2005), it is important to bear in mind the structural roots of violence in South Africa, including high levels of inequality, unemployment, and the legacy of a violent state apparatus, to avoid pathologizing or essentializing South African culture or men. Studies of African American communities in the United States have refuted claims that a "culture of poverty" is responsible for high rates of poverty and interpersonal violence in favor of an explanation grounded in theories of structural disadvantage (Almgren, 2005). Studies of violence in South Africa must similarly beware of reifying violence as a cultural norm. National-level debates have tended to overshadow the voices of abused women themselves. It is in this context that the voices of abused women are presented in this article to underscore the importance of involving abused women in the development and discussion of interventions to address violence and HIV risk in their communities.

Although qualitative literature has separately addressed the issues of violence and HIV risk, few have examined the links between violence and HIV in South Africa. This qualitative study examined women involved in abusive and controlling relationships to understand the abused woman's own experience with, and challenges posed by, attempts to implement HIV risk-reduction strategies in the abusive context.

\section{Method}

Based on existing literature on VAW and HIV risk, an in-depth, qualitative interview guide was developed to be administered to women seeking services at People Opposing Women Abuse (POWA), a well-established, Johannesburg-based, nongovernmental organization that provides services to abused women. The purpose of these interviews was to inform the development of an intervention to assist abused women in reducing their HIV risk, which could be integrated into services provided by abused women's shelters and community-based organizations. The protocol used a semistructured interview format covering specific domains related to the experiences of abuse, beliefs, and attitudes regarding HIV risk and community norms. Of specific interest were the types of abuse or other experiences for which women seek services at POWA, women's experiences with sexual negotiation in the abusive context, how women perceive abuse and HIV to interact, if at all, and community norms or customs that women believe play a role in abuse and HIV risk. ${ }^{2}$

Beginning in May 2002, counselors from POWA's six service locations in the greater Johannesburg area provided informational leaflets to active clients during a 3-month period. Adult women (aged 18 and up) interested in the study were given 
appointments to participate. A total of 27 women completed the interviews from June to August 2002, yielding 18 usable transcripts. All participants were currently attending POWA for individual counseling and other service provision. After obtaining informed consent, trained research staff conducted all interviews, which ranged from 1 to 2 hours in length. Monetary incentives equivalent to US\$7.00 were provided for their participation.

Zulu-, Sotho-, and English-speaking participants were enrolled in this study. As it is common to be fluent in several languages in South Africa, participants were asked in which of the three languages—Zulu, Sotho, or English—-they felt most comfortable conversing. Interviewers fluent in each respective language conducted the interviews and informed consent process as requested by each participant. The face-to-face interviews were audiotaped, transcribed verbatim, and then translated into English. ${ }^{3}$

Two coders, who were not involved in the interview process, systematically read each transcript to identify thematic categories related to abuse experiences and HIV risk and independently constructed a list of codes with definitions for each interview. Coders refined the coding framework into a comprehensive framework until no new thematic information or thematic relationships were identified in transcripts, and they reached consensus on codes to include and their structural relationships.

To provide readers with an idea of the relative frequency of the occurrence of the themes without imposing a false precision implied by the use of numerical frequencies, the following descriptive terms will be used: a couple, several, some, or a few (corresponding to $2-5$ people, or $11 \%-27 \%$ of cases); many (corresponding to $6-11$ people, or $30 \%-61 \%$ of the cases); and most (corresponding to $12-18$ people, or $67 \%$ or more of the cases). This approach has been used in other qualitative studies (e.g., Siegel \& Schrimshaw, 2000).

\section{Description of Sample}

The ages of the women ranged from 18 to 53, with most of the women in their 30s. All of the women lived in the greater Johannesburg area, including urban areas and surrounding townships. All were Black African, with most having Zulu or Sotho as their primary language. Of the women, 15 either were currently, or had been previously, in a long-term relationship with their primary abuser, with 10 of the 15 women having had some form of marriage (customary or civil union) with their abuser. A couple of women had experienced abuse in addition to IPV, including CSA and acquaintance rape. One woman, in particular, differed in that she had not experienced IPV. Rather, acquaintance rape had brought her to POWA. However, her responses on key issues about her relationships paralleled those of the other women closely enough that her interview was retained in the coding. About half of the women were still with their abusive partners even while attending POWA, whereas others had either left their partners or it was unclear from the interview. Several had moved on to new relationships, whereas others were not currently involved in a 
relationship, some by choice. Most (15) of the women in the sample had children, and, of these, most had children with their primary abuser. Most women were also from a moderate to low socioeconomic background, with the average educational attainment being between standard 6 and 10 (high school or some high school), with the exception of 3 who had completed some tertiary education and 2 who had achieved little to no education. Three women had formal employment, and 3 worked in the informal sector (e.g., market trading), whereas the remainder reported being unemployed. Most (15) reported earning an income of 500 Rand (approximately US\$70.00) or less per month. Many (11) of the women reported having had symptoms of and/or seeking treatment for a sexually transmitted infection (STI). Four of the 18 women in the sample reported being HIV positive, which mirrors the overall national infection rate of approximately $20 \%$ (UNAIDS, 2002).

\section{Results}

\section{Women's Experiences of Abuse}

Women experienced myriad forms of abuse, including physical, sexual, psychological, and financial. Almost all of the women reported having experienced physical abuse. Physical abuse usually involved hitting and beating, whereas individual women mentioned being punched, slapped, hit with a bottle, and soaked with cold water.

In addition to physical assault, most women had experienced some form of sexual abuse. Of these, 1 mentioned in general terms that she had been sexually assaulted, 2 had been raped by a stranger or acquaintance, 2 had endured CSA, and 11 were repeatedly raped or forced to have sex by partners. When asked if their partners had forced them to have sex without their consent, some of the women made clear their sense of violation, as exemplified in this woman's comment: "After the quarrels and the beatings that I endured, I was still forced to have sex with him. I consider that sex without consideration, in other words, rape." Men used both physical power and psychological threats to force sex. Coercive sex appeared to be an ongoing feature of these women's sexual relationships rather than a one-time violation.

Psychological and emotional abuse took many forms, and almost all women had been subjected to it, including this participant: "I have been his fool, his idiot, and his toy. He does anything to me that he wants. ... I have become his doormat.” Many women had been insulted or shouted at by their partners. Some women encountered threats, including explicit threats of murder by their partners. Some women described enduring controlling behavior, including being locked out of the house, forced to quit their jobs, and accused of infidelity. A couple suffered because of a lack of affection or consideration from their partner, including sexual neglect or being ignored by their partners. Also, some women described being upset by male infidelity, for example when men brought other partners back to their home, or had other women call and harangue them. 
Many of the women in this study referred to economic and financial abuse as having direct and severe effects, including health outcomes. Most women had encountered financial abuse in various forms, such as partners who refused to support them or who spent their own and the women's money on alcohol or other items without their consent. The partners of some women attempted to control their earnings or their jobs. The financial control and uncertainty that they experienced served as an additional source of stress in the relationship.

\section{Women's Vulnerability to HIV and Violence}

Consonant with the literature, in an area with high HIV prevalence, abuse placed these women at direct risk for HIV through forced or coercive unprotected sex with a risky partner (Maman et al., 2000). Violence and threats of violence prohibited most of these women from adopting key risk reduction techniques such as abstaining from sex, limiting their number of sexual partners, and using condoms. In addition, for many of these women, attempts at safer sex negotiation served to prompt further violence and abuse leading to a reciprocal relationship between risk for abuse and HIV.

Many participants noted that physical and sexual abuse were closely linked. Some were beaten for other reasons and then forced to have sex, whereas other women refused sex and were beaten as retribution. As such, sexual relations in the abusive context were often forced, leaving little room for negotiation. Some even described forced sex as the norm in their relationship: "The father of my kids usually forces me to sleep with him. I say, no, but he just goes on.” Furthermore, the forced nature of sex, and the trajectory of physical and sexual assault, obviated key risk-reduction strategies for many of the women, as this woman describes: "In most cases, I was forced to have sex after being beaten. I then think that it is very difficult to demand or insist on condom use between the beating and the rape."

Although the connections of physical and sexual assault posed the most direct risk for HIV, emotional and economic abuse also intertwined to inhibit HIV risk reduction efforts. For most of the women, psychological and emotional abuse, such as threats of leaving the relationship or seeking out other partners, created a climate of control that made it difficult for women to challenge their partners or sometimes made them submit to risky sex. As this woman explains,

When I asked money from him, he would first demand sex from me . . . he would say "If you have sex with me, I will buy you whatever you want." That was a condition on which he would buy me things.

Thus, financial dependence and control at times prevented women from leaving sexually risky relationships and were also used as leverage by their partners who directly and indirectly tied sexual submissiveness to economic rewards.

Furthermore, a key risk factor for women, which also composed a large element of the abusive experience, involved their partners having concurrent sexual partnerships 
during the course of their relationship. Fourteen of the 18 women reported having direct knowledge that their partner had other partners, including witnessing the act, discovering children from other women, having other women come to live in the home, developing STIs while monogamous, and having others report these behaviors to them. Many women cited male promiscuity and infidelity in relationships as being a major factor associated with HIV risk, as this woman explains: "Some of the infected persons feel that they have been robbed because innocent as I am I can get infected from sleeping with my boyfriend who sleeps around.” One woman also explained that the neglect that abused women may feel in their relationships could encourage women to seek out other partners, though she did not endorse this behavior herself. Many women also noted that they believed their partners in particular, and men in general, were opposed to condom use entirely, not just in the context of their intimate relationships but also within their casual sexual relationships. Thus, many of the women identified their partners having concurrent, unprotected sexual relationships as a primary risk factor for HIV in their relationships and for women in general.

\section{Difficulties in Sexual Communication}

The poor communication in the relationship that the abusive context engendered further compounded the women's vulnerability to HIV infection. For most of the women, attempts to negotiate safer sex not only were ineffective but also, at times, could prompt further abuse. In general, communication in their intimate relationships was difficult, but particularly around topics key to risk reduction including sexual negotiation, condom use, infidelity, and HIV and STIs.

General communication problems in the relationship made it difficult for most of the women to discuss concerns with their partners. As one woman notes, "In a good relationship where there is communication it is easy to address [problems], but in a relationship where there is no communication it will be difficult to address these problems." Poor communication contributed to an atmosphere of fear and a lack of trust: "Even if I want to ask [him] something, I feel scared.” A few women found that general communication problems or disagreements with their partners would lead to abuse.

Discussing sex, even in general terms with their partner, for many of the women, was "not a success." Talking about sex could result in fights and verbal accusations. Some women found it very difficult or impossible to bring up the topic of sex. Only a couple had mutually respectful and constructive discussions around sex with their partners. A few women commented that verbal refusal of sex had negative consequences, such as beatings or forced sex. Discussing infidelity was also problematic for some women as men would refuse to respond, dissemble, or resort to violence. For example, one woman explained that, "A woman who lives with violence or abuse ... cannot ask her man where he comes from and with whom he has been. Those questions always lead to violence and abuse.” Although women identified partner risk taking as a key HIV risk factor, discussions around this topic were considered sensitive and could at times prompt a violent response. 
Discussion of condom use also caused problems for many participants. Many women spoke about the difficulty for women, especially abused women, to discuss condom use, let alone insist on it. One difficulty associated with condom use noted in other studies (Heise \& Elias, 1995) is the implication of distrust posed by the introduction of condoms into a "committed" relationship. Despite the many examples of blatant concurrent sexual partnerships, where the topic came up, male partners immediately construed discussion of condom use as distrust. Many of the women's partners assumed they were being accused of infidelity and became defensive: "I asked him to use a condom. He asked me who told me he has got an affair." Women would feel forced to respond to the implication that they did not trust their partner rather than feeling able to assert their desire to use a condom. Alternatively, several women mentioned that they would be accused of infidelity if they tried to enforce condom use. In general, condom negotiation, when it occurred, was not successful. In addition, condom negotiation could serve as a trigger for abuse. Some of the women's partners would sometimes respond to conversations about condom use by threatening to seek out other partners "who will never force him to use condoms" or directly threatening violence.

Many of the women had discussed HIV with their partners, whereas some felt too afraid to bring the subject up or their partners refused to talk about it. Because of overall poor communication within the relationship, discussions about HIV were mainly negative and only occasionally constructive. Some partners did not believe AIDS existed, even when the women or they themselves were infected, "I would then remind him that he also has the disease and that even if he still does not believe that it is there, it is real and that he must learn to live with it.” Discussions around HIV testing were met with similar forms of denial and disbelief. One woman, who chose to reveal her HIV-positive status to a former partner, said that rather than responding with violence, her partner was disbelieving.

In discussing other STIs, many women either received negative responses, such as accusations of unfaithfulness, or could not bring this up with their partners at all. Similar to discussions of infidelity, this could also become a precursor to abuse.

I will speak to him nicely and explain that whenever I sleep with him after his visits, I get a smelly discharge or an itch. . . . He would tell me to stop accusing him of sleeping around and call me a liar. He would scream at me all the time and sometimes slap me.

Many of the women reported having experienced symptoms of an STI or having been treated for an STI, some repeatedly, after sex with their partners. Some of the women mentioned being forced to endure sex while having symptoms of an STI, as one woman describes, "I know about the 'drop.' I had it last month and I told him about it. He didn’t mind. He wanted to have sex. I told him I was feeling severe pain." Another woman described how she did not tell her partner about a case of gonorrhea she had developed and that "he was also sick but we didn't talk about it." 
This lack of communication meant that her partner did not get the treatment he needed and left open the possibility of reinfection. Infection with an STI can be considered as both an incidence of abuse and as an additional negative health consequence itself. Although infection with an STI has serious sexual, reproductive, and psychological health consequences in its own right, STI awareness and treatment are also key components in HIV prevention as their presence increases susceptibility to HIV infection (e.g., Kehinde, Lawoyin, \& Bakare, 2004; Nusbaum, Wallace, Slatt, \& Kondrad, 2004). Women's infection with STIs, and their difficulties in communicating with their partners about these infections, compounded many of the women's abusive experiences and may have increased their risk for contracting HIV.

The poor communication engendered within the abusive context inhibited women's ability to negotiate sex or condom use, placing them at risk for HIV. Many of the women expressed that it was often easier to keep quiet and endure the abusive situation than try to confront it, which might lead to further abuse. The connection of communication with abuse meant that it was extremely difficult for women to use verbal techniques to solve problems in their relationships. Although only a few women recounted personal experiences where general disagreements or verbal refusals of sex had sparked verbal attacks, physical violence, or rape, women felt that in general in relationships, communication around sex, HIV/STIs, and condom use could lead to abuse.

\section{A Social Environment Fueling Abuse and HIV Risk}

In addition to the interpersonal risk factors previously discussed within abusive relationships, community norms were found to fuel gendered power relations, which enabled abuse and compounded women's risk for violence and HIV. Just as physical, emotional, and financial abuse provided a context for coercive sex, placing women at direct risk for HIV, social and contextual factors that condoned abuse exacerbated women's vulnerability to HIV. Key factors included silence surrounding abuse, women's economic dependence on men, male substance use, repressive gender norms, and women's risk perception and behaviors, all of which impeded women's ability to exit or ameliorate the abusive situation.

Community beliefs surrounding IPV. Gauging how the women believed IPV was viewed in their communities is useful in understanding how they contextualized their own experience as a private, individual matter or as part of a larger social phenomenon. Most women expressed the opinion that abuse against women was common in their communities, whereas one woman disagreed. One woman mused that "the abuse has become a way of life for some women. Some even look at it as a custom." In addition to the general perception that abuse is common, most participants were personally acquainted with a few other women experiencing abuse. One lamented, "My friends are so used to it that they no longer care." 
Despite recognition of high community prevalence of abuse and the fact that most women knew of others being abused, many of the women still felt that domestic violence was treated as a taboo subject. Many did not feel they or others could tell anyone about the abuse and feared reactions to their disclosure. In fact, many women kept quiet about their abuse at first, hiding it from their friends, family, or caregivers, sometimes out of shame. These fears seemed to be closely tied to a "culture of silence” within their communities, which does not encourage sharing personal problems with others. A few women even lamented that this represented a discontinuity with previous community norms:

I could not discuss or share my problems with anyone as we Black people laugh and ridicule one another. We live in a "mind your own business" environment, ignore one another's problems and do not help anyone as it used to be in the olden days.

Similarly, some mentioned societal beliefs that women should endure an unhappy relationship or "suffer in silence": "It starts from our upbringing. Especially, in the African community. We Africans are advised to 'hang in there' or 'persevere' when things are tough. Especially in a marriage.” Several women quipped that pressure from elders, family, and community members to "tough out" an abusive marital relationship was a contributing factor to high levels of abuse. Several others similarly pointed to the arranged nature of their own and others' relationships as a potential perpetuator of abuse.

One woman rejected the idea of IPV being culturally sanctioned, arguing that African culture promotes respect for women:

There is a saying in Sotho that "mosadi o swara thipa ka bogaleng"-a mother is the one who can take care of the family. This means that without a mother you are nothing. And without a mother we would [not] be here, so I don't understand why men treat us like dogs.

Also, the fact that the male partner's family sometimes took his side, attacking the woman and blaming her for problems, made enlisting help or instituting change more difficult. For example, a woman described this confrontation with her in-laws:

The police took him and his sister chased me out of the house because I got [her] brother arrested. She was going on and on about that fact that I am an ungrateful woman who gets her partner arrested. She said there are many women whose partners hit them.

These family members perpetuated social norms that made abuse acceptable.

Women's economic dependence. Consonant with the literature, women in the study expressed the sentiment that women were often put at risk of violence and HIV because of their financial dependence on men. Most of the women felt that, in 
general, they were forced to endure violence, forced sex, and male infidelity because they were dependent on male earnings. Some believed that their partner exploited this dependence. Their partners could continue their abuse knowing that the women were financially tied to them. Furthermore, a woman working was seen as a threat that could undermine her subservient role in the household: "He told me I should leave my work so that I can be a housewife."

However, some women seemed to subscribe to a gender norm that expected men to financially support them. As this woman explains: "Our problem is that we like material things and we stay in bad relationships or marriages because our men have money." In this sense, this woman challenged those who remain in abusive relationships for what could be viewed as gratuitously material benefits. Some women noted that women's limited financial opportunities and economic dependence on men pressured them to engage in "survival sex," placing them at risk for HIV: "Women are at risk of contracting [HIV] because of poverty. Poor women tend to be involved in many sexual relationships with men in exchange for money for food." Interestingly, only one of the women interviewed actually noted having engaged in sex for this purpose; however, some felt that women in general might be put at risk because of this financial imperative.

Substance abuse. Substance abuse has been noted to play a role in HIV risk, where an intoxicated male is much less likely to comply with a female's condom request (Heise \& Elias, 1995). Many women felt that substance abuse was very prevalent in their communities, especially among men: "Substance abuse happens a lot, it is everywhere. Most people, especially men, are under the influence Monday to Monday." Many women specified that their male partners used alcohol, all but one to excess.

Male substance use, particularly alcohol, was intimately related to the physical, sexual, and emotional abuse of the women in this sample. Many of the women's experiences had a stark similarity: Partners would arrive home drunk and rapidly become violent or demand sex. Furthermore, women often connected their partners' substance-abuse habits with their engaging in risky sexual activity, which, in turn, could increase women's risk, as one woman explained:

He drinks and comes home very late at night. When he is out drinking, I do not know where he is and which route does he take coming back home. And when he is drunk, he does not want to use a condom.

As opposed to men, many women reported using no "drugs or substances" at all, whereas some drank in moderation. Yet in contrast to their own stated habits, many participants felt that women in general do abuse substances or alcohol, which could result in risky sexual behavior. Many women described substance use as a mechanism for coping with abuse, and their bigger concern was the substance-abuse habits of their male partners who tended to engage in substance abuse more and potentially 
engaged in more risky sexual activity while under the influence. This, in turn, put abused women at risk for both HIV and further abuse.

Repressive gender norms. Most of the women in this study commented that a communal belief in the innate supremacy of men seemed to reinforce and enable men's power over their partners. For example, one woman said, "The most common belief ... that a man is superior to a woman . . . results in men doing whatever they want to their women." This perception of socially endorsed male power was manifested at the household level: "My husband says that in his house a woman has no rights." Many of the women said their male partners held decision-making power within relationships. Overall, women lacked power: "If they want to hit us, they do. And if they want sex, they force us to. We are powerless." Thus, men were able to invoke the belief in their innate power as males to silence their partners and exert domestic control. Furthermore, there were expectations that women would provide sex for their husbands or partners. As this woman explains, "He treated me like his sex object and told me that whenever he wanted sex, he must have it. And that is that."

Other studies have noted a belief among women that men have the right to have multiple partners and that women have no right to object to this (Abdool-Karim, 2001). In this study, some of the women implied that male promiscuity was innate or that men felt it was an entitlement. It appeared that men were relatively open about having multiple partners, occasionally flaunting this behavior and challenging their partners to leave if they disagreed with their actions. Yet in contrast to the previous literature, several of the women refused to accept this social norm, as this woman explained, "It is true, but it is not right. Men should stick with their partners." Despite this resistance on the part of women, several of the women complained that the community did little to enforce social sanctions condemning IPV or male sexual entitlement.

HIV risk perception. Most women did seem to see the connections among violence, HIV risk, and their partners' infidelity, yet they identified the belief among both men and women that condoms are unnecessary in an ongoing sexual relationship. As this HIV-positive woman explains, "I used to think that I would never get HIV/AIDS since I was a married woman. I used to be very negative about it. Look at me now!” Although many of the women noted a belief that monogamous relationships were safe from contracting HIV, most did not endorse this belief themselves.

\section{Decreasing IPV as an HIV Prevention Strategy}

The complex interactions between abuse and HIV risk for women require holistic solutions. As this study was intended to inform the development of HIV prevention interventions for women who have experienced or are currently experiencing IPV, the participants were asked to discuss possible solutions to HIV risk in the abusive context. These women had many suggestions of how to reduce abuse and abused women's 
vulnerability to HIV. The most commonly noted solution was to "break the silence" around abuse and challenge the societal taboos that condone abuse and put women at heightened risk for HIV. Most of the women emphasized the importance of talking with others as both a coping mechanism to deal with their abuse and as an empowerment tool that could be used to solve the problem of IPV. Most of the women advocated that abuse victims should speak out about their experiences, either individually or en masse, to change community norms. These women had been helped through accessing services at POWA and emphasized the need for more women to access similar services.

A number of women spoke of women's empowerment, particularly through a retaking of sexual power. Women recommended refusing sex, demanding condom use, and gaining access to female condoms. As one woman said, "If a man refuses to use a condom, it is your life, just don't sleep with him at all. . . . Men don't understand things, stand up for your rights!" Many women highlighted the need to involve men in intervention strategies as women acknowledged their limited ability to implement risk reduction strategies within their intimate relationships. Because of the fact that many women felt trapped in their relationships for financial reasons, some advocated financial independence as a possible solution to their abusive relationships. Finally, many women advocated for stricter sentences to be handed down to abusive men to prevent abuse, and several women criticized the government for not "participating a lot towards abused women or towards people with AIDS."

\section{Discussion}

In their own words and from their own experiences, the women in this study convey the principle associations between IPV and women's risk for contracting HIV and yield possible solutions to address this problem. This study provides an in-depth analysis of the qualitative experiences of a sample of abused women in South Africa, lending insight into the intricacies of their vulnerability to HIV and filling a gap in the literature that points to abusive relationships as a primary pathway for HIV risk.

The difficulties that women face in negotiating safer sex with male partners have been the focus of much of the literature on gender and HIV. Wood et al. (1998) have identified a shift in the focus in qualitative literature on sexuality toward a social and dynamic perspective emphasizing micro-level decision making and negotiation within sexual relationships. Furthermore, communication within sexual encounters is seen as key to the realization of both sexual health and sexual rights, which includes the possibility of having pleasurable, mutually respectful, and safe sexual experiences, free of coercion, discrimination, and violence (WHO, 2004). If they are to achieve sexual health, women must be empowered to exercise control over their sexual lives (WHO, 2004). Most of the women in this study reported difficulties in communicating with their partners on most 
topics, and especially on sex. Communication with their partners for most of the women did not occur on an equal footing. Rather, the threat of abuse created a climate of fear and control that made meaningful communication on most any topic very difficult.

There is general recognition that VAW is rooted in gendered power relations (Flake, 2005; Jewkes, 2002; Wyatt et al., 2004). In this regard, a woman's attempt to negotiate sexual behavior represents a challenge to the male's level of control over the sexual encounter and increases the likelihood of a violent reaction as men resort to using psychological and physical IPV to exert their masculinity (El-Bassel et al., 2004). Overall, the women in this study expressed concern about their risk for HIV, particularly the risk that being in an abusive relationship posed. Most of the women identified some form of male power and control as circumscribing their own and other women's ability to engage in HIV preventive behaviors.

Although interpersonal violence occurs between individuals, increasingly research on violence theory and prevention is examining the various social levels (including macro, meso, and micro) in which violence manifests itself (James et al., 2003) and drawing on an ecological perspective to understand IPV (e.g., Heise, 1998). Farmer (2003) stresses the importance of identifying social mechanisms such as poverty, racism, and sexism that "structure" disease and violence. This study not only examined women's personal experience of abuse in relation to their intimate partners but also queried how they believed community norms affected VAW and women's HIV risk. The women in this study noted a variety of ways in which male dominance and control in relationships were reinforced through community norms that sanction abusive and controlling relationships, encouraging the woman to endure her abusive situation and validating male sexual prowess.

Furthermore, economic dependence and control among many of the women in this study served as a risk factor for HIV as women were pressured to remain in their relationships and provide sex to their partner in return for potential economic stability. Previous research has demonstrated that women, who are often economically dependent on men, may have sexual relations with men to gain access to resources otherwise unavailable. Because of this economic dependence on men, a woman has little leverage to negotiate sex or persuade a male to use condoms (Heise \& Elias, 1995). Furthermore, reports of transactional and survival sex in South Africa have revealed that women maintain sexual relations with a boyfriend as long as he provides her with money for necessities or fashionable goods (LeClerc-Madlala, 2003). However, these studies have primarily focused on "sugar daddy"-style relationships, which often occur between older men and younger girls (e.g., Luke, 2005). This study demonstrated that perceived financial abuse and control, often within marriages, was a major source of stress for many of the participants. Examining how financial difficulties within relationships may relate to IPV and HIV risk through gender role expectations, substance use, and social stress has not been as well explored as other forms of economic vulnerability in South Africa. 
Similar to previous research, this study challenges the constructions of sexual consent and free agency among women in South Africa. Previous qualitative research on adolescent sexual relationships in South Africa indicates that a norm of coercion within sexual relationships may blur the lines between wanted and unwanted sex. Despite a common belief that rape is perpetrated by strangers, some of the most common forms of sexual violence may include instances in which sex is agreed to after threats in marriages, dating relationships, and families (Wood et al., 1998). Sexual coercion in these forms may not involve direct force and may ultimately be consensual but still result in unwanted sexual intercourse (Jewkes \& Abrahams, 2002). Yet although most of the women in this study identified expectations that they should provide sex for their partners, unlike previous studies many of the women also expressly noted feeling violated by the violence they experienced.

In a similar vein, one of the concerning findings of this study is that women in theoretically monogamous, closed sexual relationships may be put at risk for HIV and other STIs by the high-risk behaviors of their partners over which they have little or no control. As Heise and Elias (1995) note, women may believe that they are safe from the disease because they remain with only one partner and therefore do not use protection; however, with the acceptance of male sexual behaviors such as multiple partners, women in fact are not safe from the infection. Furthermore, recent quantitative evidence also points to married and cohabitating women's elevated risk for HIV in South Africa (e.g., Ali, Cleland, \& Shah, 2004; Maharaj \& Cleland, 2004), primarily for this same reason. Evidence from the present study, however, indicates that these abused women, including two thirds of the sample in marital relationships, did not underestimate their risk for HIV infection. Rather, most identified the behaviors of their partners as their primary risk factor, over which they had little control because of the violent context of their relationships.

This study has several limitations that should be noted. First, as this is an in-depth exploration of a small group of abused women from around Johannesburg, its generalizability to other groups, including nonabused women, women who have experienced abuse other than IPV, and those coming from different parts of the country or world, is limited. Although there are likely commonalities among women who experience IPV, the context of the abuse may vary significantly in other communities. Second, the women in this study represent a self-selected group who have already sought assistance and counseling at POWA and through other outlets. It is probable that these women are more knowledgeable and empowered than women who have not sought or received help for IPV. This fact should also be considered when interpreting the women's reports of community norms surrounding abuse.

The self-reported nature of women's own stated risk behaviors may be a potential source of bias if social desirability factors made women uncomfortable disclosing their own sexual risk taking apart from that of their partners. The women in this study tended to portray their partners as their primary source of HIV risk. It is therefore 
important to note that although VAW is inherently gendered, HIV risk pertains to both men and women. Although women may be at elevated risk for HIV in sub-Saharan Africa, the same gender norms that place women at risk also affect men. Norms of male sexual prowess, dominance, and control circumscribe men's ability to engage in protected sexual behaviors. A continued focus on women's HIV risk alone could lead to the inaccurate belief that women are more susceptible to HIV infection than are men and fuel further VAW.

\section{Implications for Intervention}

Given that the women in this study had a difficult time communicating with their partners about practicing safer sex and may have had a genuine desire to engage in unprotected intimacy with their partner, more research on microbicides as a potentially effective alternative to male-controlled condoms is important. In addition, more research should be conducted to determine the prevalence of sero-discordant couples and how to involve male partners in HIV- and IPV-prevention interventions. Although the need for working with men to prevent VAW and HIV in South Africa has been well documented (e.g., Wood \& Jewkes, 1997), progress in this important direction has been slow. The results of this study reinforce the need to conduct research and interventions with men in general, and abusive men in particular, to address the gender norms that condone and encourage sexual risk taking. Similarly, given that many of the women in the study suggested involving men in HIV prevention interventions, the feasibility of conducting interventions with couples should be assessed.

This study further reveals the reciprocal nature of risk within the abusive context. Abuse directly places women at risk for HIV through forced sex, and attempts to implement risk-reduction strategies can make women vulnerable to further abuse. Thus, interventions aimed at encouraging women to reduce their high-risk behavior and seek out HIV testing must take into account the dangers posed by implementing safer sex and possibly revealing their HIV-positive status. Yet at the same time, because abused women are a group that is particularly vulnerable to HIV infection, HIV risk-reduction education and HIV counseling and testing referrals should be a routine part of services offered at abused women's shelters and service providers. This underscores the importance of expanding service provision to assist abused women and approach HIV prevention from a gendered perspective. More research must be done on how best to reach women who are not seeking services for abuse and strategies to address general community norms that sanction abuse. This study is important and unique in that it weaves together the multiple levels of risk that women experience, at both the individual and community levels, to yield a panorama of women's vulnerability_-both for HIV and for continued violence. 


\section{Notes}

1. According to Paiva (2003), the use of the term vulnerability represents a transition from the individualistic and antagonistic notion of risk groups and practices to an emphasis on the structural forces beyond an individual's control, such as poverty and gender inequality, which may make one vulnerable to HIV infection. Nevertheless, this article will use both risk and vulnerability.

2. It should be noted that women were asked about both their own experiences of abuse and about their perceptions of abusive relationships generally. In addition, women often responded to questions about their abusive experiences by speaking in global terms about abused women. This may be the result of translation, and these quotations may signify their own experiences or their perceptions of women who have experienced abuse generally.

3. Translators were not used to conduct interviews. Interviewers were Black South Africans fluent in Zulu, Sotho, and English.

\section{References}

Abdool-Karim, Q. (2001). Barriers to preventing human immunodeficiency virus in women: Experiences from Kwa-Zulu Natal, South Africa. Journal of the American Medical Women's Association, 56(4), 193-196.

Ali, M. M., Cleland, J., \& Shah, I. H. (2004). Condom use within marriage: A neglected HIV intervention. Bulletin of the World Health Organization, 82, 180-186.

Almgren, G. (2005). The ecological context of interpersonal violence: From culture to collective efficacy. Journal of Interpersonal Violence, 20, 218-224.

Amfar. (2005). Gender-based violence and HIV among women: Assessing the evidence (Issue brief no. 3). New York: Author.

Department of Health. (1998). South African Demographic and Health Survey. Medical Research Council. Retrieved July 1, 2005, from http://www.mrc.ac.za/bod/dhsfin1.pdf

Dunkle, K. L., Jewkes, R. K., Brown, H. C., Gray, G. E., McIntryre, J. A., \& Harlow, S. D. (2004). Gender-based violence, relationship power, and risk of HIV infection in women attending antenatal clinics in South Africa. Lancet, 363, 1415-1421.

El-Bassel, N., Gilbert, L., Golder, S., Wu, E., Chang, M., Fontdevila, J., et al. (2004). Deconstructing the relationship between intimate partner violence and sexual HIV risk among drug-involved men and their female partners. AIDS and Behavior, 8, 429-439.

Farmer, P. (2003). Pathologies of power: Health, human rights, and the new war on the poor. Berkeley: University of California Press.

Flake, D. F. (2005). Individual, family, and community risk markers for domestic violence in Peru. Violence Against Women, 11, 353-373.

Flinck, A., Paavilainen, E., \& Åstedt-Kurki, P. (2005). Survival of intimate partner violence as experienced by women. Journal of Clinical Nursing, 14, 383-393.

Gilbert, L. (1996). Urban violence and health, South Africa, 1995. Social Science and Medicine, 43, 873-886. 
Gilbert, L., \& Walker, L. (2002). Treading the path of least resistance: HIV/AIDS and social inequalitiesA South African case study. Social Science and Medicine, 54, 1093-1110.

Gupta, G. R., \& Weiss, E. (1993). Women's lives and sex: Implications for AIDS prevention. Culture, Medicine and Psychiatry, 17, 399-412.

Heise, L. (1998). Violence against women: An integrated, ecological framework. Violence Against Women, 4, 262-290.

Heise, L. L., \& Elias, C. (1995). Transforming AIDS prevention to meet women’s needs: A focus on developing countries. Social Science and Medicine, 40, 931-943.

Heise, L., Ellsberg, M., \& Gottmoeller, M. (2002). A global overview of gender-based violence. International Journal of Gynecology \& Obstetrics, 78, 5-14.

Human Rights Watch. (1995). Violence against women in South Africa: State response to domestic violence and rape. New York: Author.

James, S. E., Johnson, J., Raghavan, C., Lemos, T., Barakett, M., \& Woolis, D. (2003). The violent matrix: A study of structural, interpersonal, and intrapersonal violence among a sample of poor women. American Journal of Community Psychology, 31, 129-141.

Jewkes, R. (2002). Preventing sexual violence: A rights-based approach. Lancet, 360, 1092.

Jewkes, R. K., \& Abrahams, N. (2002). The epidemiology of rape and sexual coercion in South Africa: An overview. Social Science and Medicine, 55, 1231-1244.

Jewkes, R. K., Penn-Kekana, L., Levin, J., Ratsaka, M., \& Schrieber, M. (2001). Prevalence of emotional, physical and sexual abuse of women in three South African provinces. South African Medical Journal, 91, 421-428.

Jewkes, R. K., Vundule, C., Maforah, F., \& Jordaan, E. (2001). Relationship dynamics and teenage pregnancy in South Africa. Social Science and Medicine, 52, 733-744.

Kehinde, A. O., Lawoyin, T. O., \& Bakare, R. A. (2004). Risk factors for HIV infection among special treatment clinic attendees in Ibadan, Nigeria. African Journal of Medicine and Medical Sciences, 33, 229234.

Leclerc-Madlala, S. (2003, August). Modernity, meaning and money: Urban youth and the commodification of relationships. Paper presented at the 1st South African AIDS Conference, ICI, Durban, South Africa.

Luke, N. (2005). Confronting the "sugar daddy" stereotype in urban Kenya. International Family Planning Perspectives, 31(1), 6-14.

Maharaj, P., \& Cleland, J. (2004). Condom use within marital and cohabiting partnerships in KwaZuluNatal, South Africa. Studies in Family Planning, 35, 116-124.

Maman, S., Campbell, J., Sweat, M. D., \& Gielen, A. C. (2000). The intersections of HIV and violence: Directions for future research and interventions. Social Science and Medicine, 50, 459-478.

Nusbaum, M. R., Wallace, R. R., Slatt, L. M., \& Kondrad, E. C. (2004). Sexually transmitted infections and increased risk of co-infection with human immunodeficiency virus. Journal of the American Osteopathic Association, 104, 527-535.

Obermeyer, C. M. (2005). Reframing research on sexual behavior and HIV. Studies in Family Planning, 36(1), 1-12.

Outwater, A., Abrahams, N., \& Campbell, J. (2005). Women in South Africa, intentional violence and HIV: Intersections and prevention. Journal of Black Studies, 35(4), 135-154. 
openUP

Paiva, V. (2003). Beyond magical solutions: Prevention of HIV and AIDS and the process of psychosocial emancipation. Divulgacao em Saude para Debate, 27, 192-203.

Parker, R. (2000). Administering the epidemic: HIV/AIDS policy, models of development, and international health. In L. M. Whiteford \& L. Manderson (Eds.), Global health policy, local realities: The fallacy of the level playing field (pp. 39-55). London: Lynne Rienner.

Roth, N. L., \& Hogan, K. (1998). Gendered epidemic: Representations of women in the age of AIDS. New York: Routledge.

Santow, G. (1995). Social roles and physical health: The case of female disadvantage in poor countries. Social Science and Medicine, 40, 147-161.

Siegel, K., \& Schrimshaw, E. W. (2000). Coping with negative emotions: The cognitive strategies of HIVinfected gay/bisexual men. Journal of Health Psychology, 5, 517-530.

Umerah-Udezulu, I. (2001). Resensitizing African health care and policy practitioners: The gendered nature of AIDS epidemics in Africa. Jenda: A Journal of Culture and African Women's Studies, 1(2), 1530-5686.

UNAIDS. (2002) South Africa: Epidemiological fact sheets on HIV/AIDS and sexually transmitted infections, 2002 update, fact sheet. New York: Author.

UNAIDS. (2003). Questions and answers II: Basic facts about the HIV/AIDS epidemic and its impact. New York: Author.

Watts, C., \& Zimmerman, C. (2002). Violence against women: Global scope and magnitude. Lancet, 359, 1232-1237.

Wood, K., \& Jewkes, R. K. (1997). Violence, rape, and sexual coercion: Everyday love in a South African township. Gender and Development, 5(2), 41-46.

Wood, K., Maforah, F., \& Jewkes, R. K. (1998). He forced me to love him: Putting violence on adolescent sexual health agendas. Social Science and Medicine, 47, 233-242.

World Health Organization. (2000). Women and HIV/AIDS fact sheet no. 242. Retrieved September 1, 2003, from http://www.who.int/inf-fs/en/fact242.html

World Health Organization. (2002). World report on violence and health. Geneva, Switzerland: Author.

World Health Organization. (2004). Sexual health: A new focus for WHO. Progress in Reproductive Health Research Newsletter, 67, 1-8.

Worth, D. (1989). Sexual decision-making and AIDS: Why condom promotion among vulnerable women is likely to fail. Studies in Family Planning, 20, 297-307.

Wyatt, G. E., Longshore, D., Chin, D., Vargas Carmona, J., Burns Loeb, T., Myers, H. F., et al. (2004). The efficacy of an integrated risk reduction intervention for HIV-positive women with child sexual abuse histories. AIDS and Behavior, 8, 453-462. 